\title{
Editorial
}

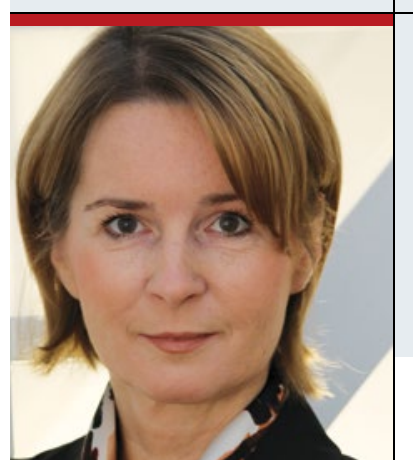

Katja Kupfer Geißler

Chefredaktion

katja.kupfer@springer.com

facebook.com/heilberufe

\section{Alle Jahre wieder?}

$\mathrm{n}$ der Redaktion ist ja immer was los - insbesondere vor Weihnachten. Jedes Jahr nehmen wir uns vor, dass wir dieses Jahr ganz bestimmt mal mehr haben wollen von der besinnlichen Vorweihnachtszeit. Aber dann kommt so viel dazwischen: Planungsmeetings, Neuerungen, noch eine Pressekonferenz - und denkt dran: wenn alle im Weihnachtsurlaub sind, wird es schwer, die Autoren für die Freigaben zu erreichen. Daher besser vorher fertig werden. Aber das kennen Sie sicher auch. Denn auf den Stationen oder in Ihrem ambulanten Dienst wird es ähnlich „besinnlich“ sein. Also, alle Jahre wieder?

In diesem Jahr nicht. Die Ereignisse der letzten Monate mit Hunderttausenden von Flüchtlingen nicht nur in Deutschland, ganz zu schweigen von den Attentaten in Paris, lassen vermutlich alle nachdenklich in die Zukunft blicken. Was sie sich wünscht und wie es sein wird, Weihnachten in der Notunterkunft, fragten wir daher eine ehrenamtlich tätige Krankenschwester in Berlin (Seite 42)?

Wissen Sie, was ein Poetry Slam ist? Ein Dichterwettstreit, bei dem selbstgeschriebene Texte innerhalb einer bestimmten Zeit vorgetragen werden und das Publikum einen Sieger kürt. Einer der bekanntesten Slamer ist Lars Ruppel. Ich liebe sein Gedicht „Der alte Schwede“. Weil er aber nicht nur Gedichte vortragen will, hat er das Projekt „Weckworte“ ins Leben gerufen (Seite 46). In seinen Workshops lernen Schüler, Pflegende oder Angehörige, wie man Gedichte für Menschen mit Alzheimer oder geistiger Behinderung vorträgt, Lebensfreude weckt und so eine kulturelle Brücke bildet über Generationen hinweg.

\section{Eine frohe Weihnachtszeit und ein glückliches 2016!}

Ihre

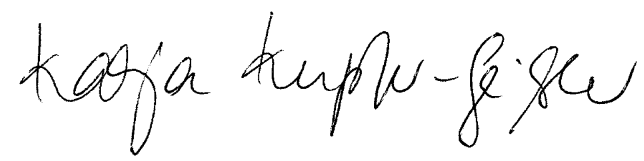

Die erste HEILBERUFE im neuen Jahr erscheint erst am 11.1.2016. Die Ausgabe widmet sich ausführlich den Themen des Kongresses „Pflege 2016“. Der Berliner Kongress findet statt vom 22. bis 23. Januar.

\section{IN EIgENER SACHE - PFLEgEKOLLEg}

Wir haben eine Bitte: Egal, ob Sie online oder postalisch an unserer beliebten Fernfortbildung PflegeKolleg teilnehmen - 2016 werden wir unsere technischen Systeme umstellen. Dann wird Ihre im System hinterlegte E-Mail-Adresse, da sie eindeutig ist, zum Benutzernamen. Doch nicht alle Nutzer haben eine E-Mail-Adresse angegeben und viele Teilnehmer (z.B. eines Pflegedienstes) nutzen dieselbe Adresse. Zukünftig benötigen wir aber pro Teilnehmer eine singuläre E-MailAdresse, damit Sie sich problemlos auf www.heilberufe.de einloggen und weiter am PflegeKolleg teilnehmen können. Diese E-Mail-Adresse können Sie selbst eintragen oder uns zusenden, damit wir sie eintragen.

Fragen? Schicken Sie uns bitte eine E-Mail: heilberufe@springer.com Oder rufen Sie uns einfach an! Tel.-Nr.: 030827875500. 